CASE REPORT

\title{
Active inflammatory bowel disease and coronary artery dissection
}

\author{
M Srinivas, P Basumani, R Muthusamy, N Wheeldon
}

Postgrad Med J 2005;81:68-70. doi: 10.1136/pgmj.2004.018952

The case of a young woman with flare-up of Crohn's disease, who had an acute myocardial infarction due to the spontaneous dissection of the left anterior descending coronary artery, is reported. The literature on this rare condition is reviewed and a mechanism postulated for spontaneous coronary artery dissection in inflammatory bowel disease.

S pontaneous coronary artery dissection is an uncommon condition, presenting as chest pain with features of acute myocardial infarction, acute coronary syndrome, or cardiogenic shock. We report the case of a young woman with flare-up of Crohn's disease, who subsequently developed features of acute myocardial infarction due to spontaneous dissection of the left anterior descending (LAD) coronary artery. To our knowledge, there are no case reports of spontaneous coronary artery dissection in active inflammatory bowel disease in the medical literature.

\section{CASE HISTORY}

A 35 year old Caucasian woman was admitted with a four day history of bloody diarrhoea, vomiting, and abdominal pain. There was no fever, chest pain, palpitations, or shortness of breath. There were no epidemiological risk factors for infective diarrhoea. Crohn's disease was diagnosed in 1995, involving small bowel and transverse and descending colon, based on radiological findings (barium enema and ultrasonography). There had been only one admission, in 2000, since diagnosis. The only risk factor for coronary artery disease was smoking 10 cigarettes daily for 11 years. At the time of this admission, she was on maintenance treatment with balsalazide and a reducing course of prednisolone (10 mg once a day), started for a recent flare. Physical examination was unremarkable except for mild epigastric tenderness with no signs of intestinal obstruction, abdominal mass, or organomegaly. Clinically, a differential diagnosis of flare-up of Crohn's disease or infective diarrhoea was considered.

Laboratory investigations (reference range), on admission, revealed a white cell count of $18.3(4-11) \times 10^{9} / 1$ with predominant neutrophilia, platelet count 485 (150-400) $\times 10^{9} / 1$, plasma viscosity $1.89(1.46-1.81)$, C-reactive protein $274(\mathrm{l}-10) \mathrm{mg} / \mathrm{l}$, albumin $25(34-46) \mathrm{g} / \mathrm{l}$, aspartate aminotransferase (AST) 159 (13-37) IU/l, creatinine 242 (55-96) $\mu \mathrm{mol} / \mathrm{l}$, and urea $9.1(2.8-7.4) \mathrm{mmol} / \mathrm{l}$. Chest and abdominal radiographs were normal. Stool samples for microscopy, culture, and Clostridium difficile cytotoxin were subsequently reported negative. Creatine kinase and electrocardiography were not done on admission as cardiac pathology was not suspected.

On the first day she was treated with intravenous fluids, antiemetics, and metronidazole. However, on the second day, the patient developed palpitations and central chest pain without haemodynamic compromise. An electrocardiogram revealed sinus rhythm and, surprisingly, ST segment elevation in Vl-V3 leads and $\mathrm{Q}$ waves in $\mathrm{Vl}-\mathrm{V} 3$ and aVL, suggestive of a recent anteroseptal myocardial infarction (fig 1). Creatine kinase was raised at 1320 (29-198 IU/1) and troponin T $5.58(<0.1 \mathrm{ng} / \mathrm{ml})$. The patient was not considered for thrombolysis because of bloody diarrhoea with active colitis, but she was transferred to the South Yorkshire Cardiothoracic Centre at Sheffield for primary angioplasty.

Coronary angiography revealed spontaneous dissection of the proximal LAD artery extending over a large diagonal vessel (fig 2). The LAD was stented and the diagonal artery was angioplastied. The rest of the coronaries were normal.

She made an uneventful recovery and the flare-up of Crohn's disease settled with an increased dose of prednisolone (30 mg once a day). On day 7, the C-reactive protein had dropped to 13 from $274 \mathrm{mg} / \mathrm{l}$ with complete normalisation of full blood count, renal and liver function.

An echocardiogram showed a left to right shunt through a small atrial septal defect with no chamber enlargement and normal left ventricular function. An optimal exercise test at six weeks was negative for exercise induced ischaemia and arrhythmia. At a recent review, nine months later, the patient remains asymptomatic with good control of the inflammatory bowel disease and no recurrence of chest pain.

\section{DISCUSSION}

Spontaneous coronary artery dissection was first described by Pretty in $1931 .^{1}$ The majority of the patients are women in their $30 \mathrm{~s}$ and at least one third are pregnant or postpartum. ${ }^{23}$ Causes of spontaneous coronary artery dissection include systemic hypertension, coronary spasm, aortic root dissection, fibromuscular hyperplasia, Marfan's syndrome and connective tissue diseases, but in several cases no cause has been identified (idiopathic). Coronary artery dissection has also been reported during coronary angiography, percutaneous coronary interventions, bypass surgery, and blunt trauma to the chest. ${ }^{4}$ There is one case report of coronary artery dissection after prolonged retching. ${ }^{5}$ Left coronary artery involvement is commoner in women and right coronary artery in men. The LAD artery is affected in $80 \%$ followed by the right coronary artery and the left circumflex artery. ${ }^{67}$ Our patient is the first reported case of coronary artery dissection in inflammatory bowel disease to the best of our knowledge. She did not have any of the previously mentioned causes of coronary artery dissection. It is quite possible that the dissection was idiopathic or induced by an early atheroma because of smoking. This was not demonstrated on angiography and an intravascular ultrasound was not indicated in this case. Features supportive of a flare-up of Crohn's disease in this patient were polymorphonuclear

Abbreviations: AST, aspartate aminotransferase; LAD, left anterior descending 


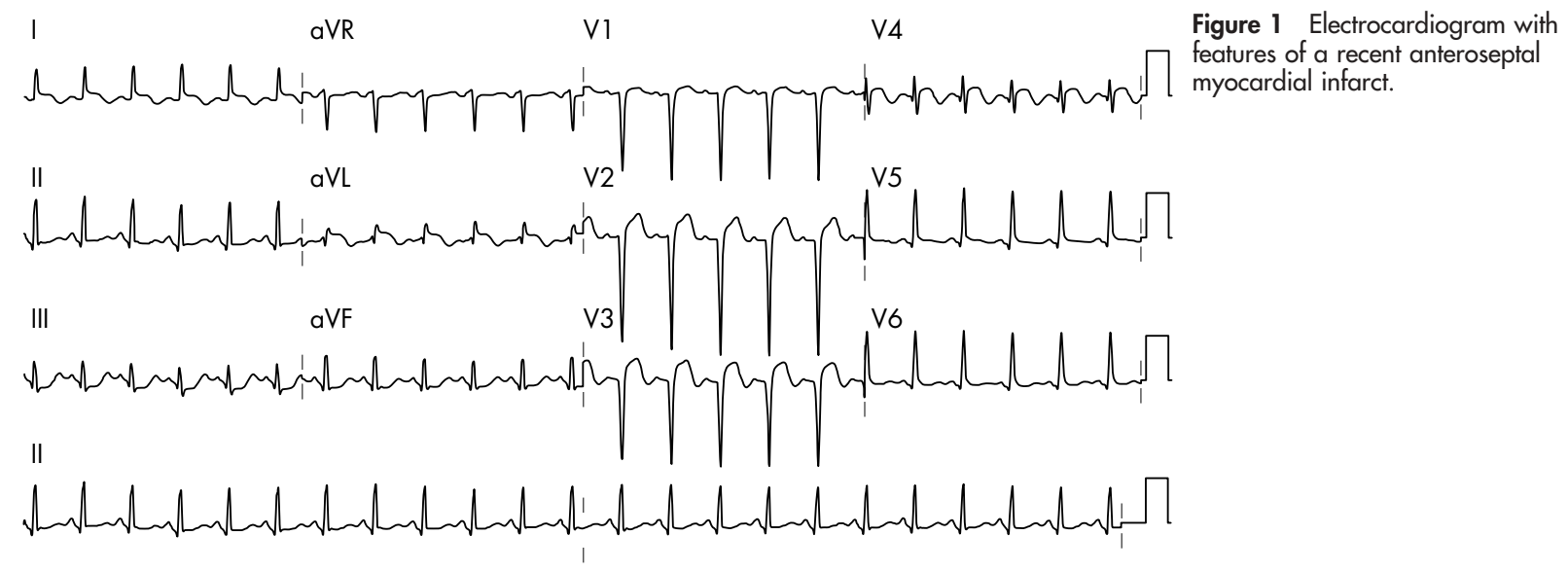

leucocytosis, thrombocytosis, and hypoalbuminaemia. The steep rise in C-reactive protein in our patient was probably reflective of the inflammation in the gut and the site of coronary dissection. This is supported by a drop in C-reactive protein to $50 \mathrm{mg} / \mathrm{l}$ within 72 hours of LAD stenting, without an increase in the dose of prednisolone. Subsequently, a further drop in C-reactive protein to almost normal levels and control of diarrhoea was achieved by increasing prednisolone to $30 \mathrm{mg}$ daily. The LAD may have been dissecting asymptomatically on admission or earlier, compromising coronary blood flow, as evidenced by a disproportionately high AST on the day of admission. The patient developed symptoms 24 hours later, when the dissection had become severe enough to cause flow restriction in the LAD artery territory.

Crohn's disease is a well recognised prothrombotic state causing venous and arterial thromboses. ${ }^{8}$ Histological evidence in Crohn's disease and coronary artery dissection support inflammatory cell infiltration in the affected cell walls. It remains debatable if it is the cause or effect in the latter. ${ }^{89}$ We postulate that active Crohn's disease may predispose patients to spontaneous coronary artery dissection by the release of proinflammatory cytokines causing intramedial haemorrhage and thrombosis due to rupture of vasa vasorum. ${ }^{10}$ The luminal pressure exerted by the shearing effect of this intramedial damage, in a normal coronary artery, can lead to dissection due to the absence of the stenting effect of an atheroma. Continued smoking probably contributed to the

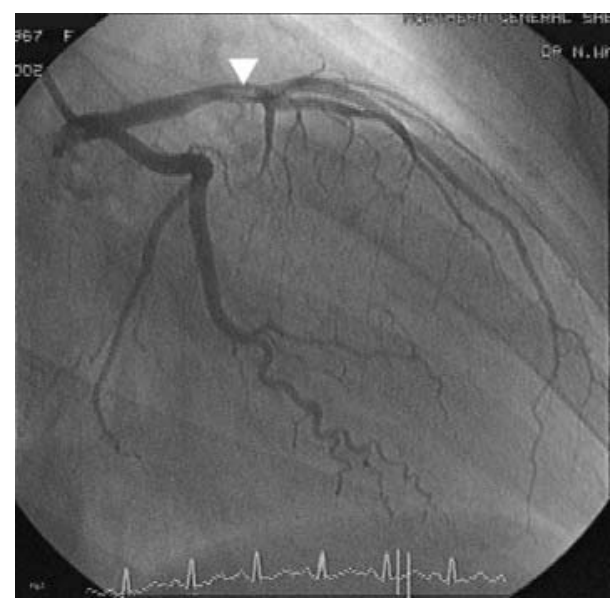

Figure 2 Coronary angiogram showing LAD dissection extending over a marginal artery (white block arrowhead).

\section{Learning points}

- Spontaneous coronary artery dissection is uncommon, but can be fatal.

- It should be suspected in young female patients with chest pain and electrocardiographic changes consistent with myocardial infarction in the absence of significant risk factors for coronary artery disease.

- Crohn's disease, due to its proinflammatory predisposition, may precipitate coronary artery dissection by cytokine release and this aspect needs further research.

severity of the flare-up of Crohn's disease, vascular inflammation, and thrombogenicity in this case.

\section{CONCLUSION}

This case highlights the silent progress of dissection to critical stenosis. In many cases of sudden death due to spontaneous coronary dissection, the diagnosis is made only at necropsy. While idiopathic coronary artery dissection is probable, active systemic inflammation is a possible aetiology for spontaneous coronary artery dissection in our patient with otherwise normal coronary arteries. Spontaneous coronary artery dissection may be yet another extraintestinal manifestation of Crohn's disease.

\section{Authors' affiliations}

M Srinivas, P Basumani, Department of Gastroenterology, Rotherham District General Hospital, Rotherham, UK

R Muthusamy, Department of Cardiology, Rotherham District General Hospital, Rotherham, UK

N Wheeldon, South Yorkshire Cardiothoracic Centre, Sheffield, UK

Correspondence to: Dr M Srinivas, Department of Gastroenterology, Rotherham District General Hospital, Moorgate Road, Rotherham S60 2UD, UK; drsrinivasm@hotmail.com

Submitted 10 January 2004

Accepted 11 April 2004

\section{REFERENCES}

1 Pretty HC. Dissecting aneurysm of coronary artery in a woman aged 42. BMJ 1931 ;i:667

2 Basso C, Morgagni GL, Thiene G. Spontaneous coronary artery dissection: a neglected cause of acute myocardial ischaemia and sudden death. Heart 1996;75:451-4.

3 Bac DJ, Lotgering FK, Verkaaik AP, et al. Spontaneous coronary artery dissection during pregnancy and post partum. Eur Heart $J$ 1995; 16:136-8. 
4 Bruce F. Waller, Non-atherosclerotic coronary heart disease. In: Valentin F ed. Hurst's the heart. 10th Ed. New York: McGraw-Hill, 2001;6(39).

5 Velusamy M, Fisherkeller M, Keenan ME, et al. Spontaneous coronary artery dissection in a young woman precipitated by retching. J Invasive Cardiol 2002;14:198-201.

6 Cohen DE, Strimike CL. A case of multiple spontaneous coronary artery dissections. Catheter Cardiovasc Interv 2002;49:318-320 [Medline].

7 Kearney P, Singh H, Hutter J, et al. Spontaneous coronary artery dissection: a report of three cases and review of the literature. Postgrad Med J 1993;69:940-5.
8 Sands BE. Crohn's disease. In: Feldman M, Friedman LS Sleisenger MH, eds. Sleisenger and Fordtran's gastrointestinal and liver diseases. 7th Ed. Philadelphia: W B Saunders, 2002;10(103):2005-38

9 Robinowitz M Virmani R, McAllister HA Jr. Spontaneous coronary artery dissection and eosinophilic inflammation: a cause and effect relationship? Am J Med 1982;72:923-8.

10 Barger AC, Beeuwkes R 3rd, Lainey LL, et al. Hypothesis: vasa vasorum and neovascularization of human coronary arteries. N Engl J Med 1984;310:175-7.

Committee on Publication Ethics Seminar 2005 Friday 11 March 2005, 9.30 am - 5 pm, BMA House, London

This year's seminar will focus on COPE's new Code of Conduct for Editors and interactive workshops on common ethical and editorial dilemmas. The seminar is for editors, authors, and all those interested in increasing the standard of publication ethics.

The Code aims to set a new basic standard for the ethical conduct of editors and sets out guidelines for quality and correcting the record, standing by decisions made, ethics committee approval, consent for publication confidentiality of submitted material, guidance to authors, pursuing misconduct, relationship to publishers, owners, and advertisers, and conflict of interest. The code also creates a mechanism to refer a complaint to COPE if an editor has breached the code.

The seminar will include:

- The new Code of Conduct for Editors

- Dr lona Heath, Chair BMJ Ethics Committee-research, audit, and ethics committee approval

- COPE's new website-full text and keyword searching for COPE's advice on specific issues, for example research misconduct, conflict of interest, and deception

- Interactive workshops - common ethical and editorial dilemmas for editors

- Opportunities to network with other editors and share your experiences and challenges

The seminar is free for COPE members and $£ 30.00$ for non-members. Numbers are limited and early booking is advisable. For registrations or more information please contact Sam Knottenbelt at cope@bmigroup.com or call 0207383 6602. For more information on COPE see www.publicationethics.org.uk/ 